\title{
Ulnar articular surface 3-D landmarks and ecomorphology of small mammals: a case study of two early Miocene typotheres (Notoungulata) from Patagonia
}

\author{
Nahuel A. Muñoz ${ }^{1,5}$, Guillermo H. Cassini ${ }^{3,4,5}$, Adriana M. Candela ${ }^{2,5}$ and \\ Sergio F. Vizcaíno ${ }^{1,5}$
}

${ }^{1}$ División Paleontología Vertebrados, Museo de La Plata, Unidades de Investigación Anexo Museo, FCNyM-UNLP, 60 y 122, 1900 La Plata, Argentina.

Email: nahuelmunoz@fcnym.unlp.edu.ar; vizcaino@fcnym.unlp.edu.ar

${ }^{2}$ División Paleontología Vertebrados, Museo de La Plata, Paseo del Bosque s/n, 1900 La Plata, Argentina.

Email: acandela@museo.fcnym.unlp.edu.ar

${ }^{3}$ División Mastozoología, Museo Argentino de Ciencias Naturales "Bernardino Rivadavia", Ciudad Autónoma de Buenos Aires, Argentina.

Email: gcassini@macn.gov.ar

${ }^{4}$ Departamento de Ciencias Básicas, Universidad Nacional de Luján, Luján, Buenos Aires, Argentina.

${ }^{5}$ CONICET. Consejo Nacional de Investigaciones Científicas y Técnicas.

\begin{abstract}
Articular surfaces reflect the relative movements between adjacent bones, and the ones involved in the elbow joint provide information about forelimb movements and may be useful for making inferences about the substrate use. The proximal articular surface of the ulna was examined through 3-D geometric morphometrics, in order to assess its usefulness as a proxy for paleoecological interpretations; particularly for two small mammals from the early Miocene of Patagonia. The sample was composed of 22 extant small mammals (rodents, carnivorans and primates) and two extinct typotheres: Hegetotherium mirabile (Hegetotheriidae) and Interatherium robustum (Interatheriidae). Forty-five landmarks were taken and principal component analysis (PCA) was used to explore the morphospace structure. The results of PCA for the whole surface were inconclusive; therefore, successive analyses were made, subdividing the surface into sub-units. The PCA for the proximal part of the trochlear notch was the most informative, allowing the recognition of morphospaces with functional value: one for digging rodents and another for most climbers. Neither typothere would have had a specialisation for climbing or digging in the features analysed. This study allows morphological patterns on different parts of a joint to be detected; interpreted, at least partially, as differential responses to different kinds of mechanical stress.
\end{abstract}

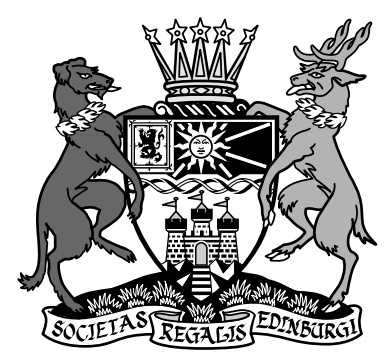

KEY WORDS: Functional morphology, geometric morphometrics, palaeobiology, substrate use

Articular surfaces of limb bones are very informative in morphofunctional studies, providing insights about the relative movements between adjacent bones. Consequently, they are a main subject in many contributions on the limbs of extant and extinct tetrapods (Jenkins 1973; Argot 2001; Szalay \& Sargis 2001; Sargis 2002; Candela \& Picasso 2008; Toledo et al. 2013). In mammals, the elbow joint is a particularly complex hinge, widely used to characterise the forelimb functionality (Jenkins 1973; Argot 2001; Andersson 2004; Candela \& Picasso 2008; Drapeau 2008; Ercoli et al. 2012; Fabre et al. 2013), because it is involved in flexion-extension movements between humerus and ulna, as well as rotational movements between these two and the radius. This triosseal relationship is clearly reflected in the proximal ulnar articular surface, making it a particularly interesting feature to study.

Studies on the correlation between form and function of the limbs usually rely on classifications in locomotor categories. However, there is much controversy about the category, or categories, in which an animal should be classified; generally because the terms used do not always describe strictly locomotion, but rather other aspects of the relation of the animal with the substrate. Miljutin (2009) claimed that, frequently, the typology of ecological strategies used is logically incorrect, sometimes mixing essentially different terms; for instance, using 'aquatic' and 'fossorial' instead of 'aquatic and subterranean' (habitat) or 'natatorial and fossorial' (locomotion) in the same classification. Furthermore, in relation to the correlation between form and function, Toledo et al. (2012) highlighted the difference between substrate preference (arboreal, terrestrial, etc.) and substrate use (climbing, digging, etc.), noting that substrate preference categories are frequently used as locomotor categories, although they are not locomotor modes.

Morphofunctional studies on extinct species normally require the study of extant species, to validate hypotheses on the function of the feature of interest. In the last decade, a considerable focus has been made on the palaeobiology of early Miocene palaeocommunities of Patagonia, using this approach (see Vizcaíno et al. 2012 and chapters therein). Amongst the characteristic mammals in this assemblage are the South American native ungulates. Their phylogenetic affinities have been controversial; Horovitz (2004) found no association with any particular modern mammal order and proposed a polyphyletic origin for the South American native ungulates. Other authors related them to Afrotheria (O'Leary et al. 2013) and, recently, 
Table 1 Species of the sample, numerical code used in the PCAs, taxonomic group (order), substrate use and specimen number.

\begin{tabular}{|c|c|c|c|c|}
\hline Code & Order & Species & Substrate use & Specimen \\
\hline 1 & Rodentia & Cuniculus paca & ambulatory & MMP-Ma 22 \\
\hline 2 & Rodentia & Callosciurus erythraeus & climber & MACN 23565 \\
\hline 3 & Rodentia & Coendou villosus & climber & MCN 2681 \\
\hline 4 & Rodentia & Ctenomys australis & digger & MLP 7.XI.95.7 \\
\hline 5 & Rodentia & Dasyprocta azarae & runner & CNP 896 \\
\hline 6 & Rodentia & Dolichotis patagonum & runner & MLP 252 \\
\hline 7 & Rodentia & Hystrix cristata & ambulatory & MACN 5.51 \\
\hline 8 & Rodentia & Lagidium viscacia & jumper & MLP 29.XII.00.3 \\
\hline 9 & Rodentia & Lagostomus maximus & digger & MLP 27.IV.95.1 \\
\hline 10 & Rodentia & Myocastor coipus & digger & MLP 09.IX.97.02 \\
\hline 11 & Carnivora & Arctictis binturong & climber & MACN 43.67 \\
\hline 12 & Carnivora & Conepatus chinga & ambulatory & MLP 1.II.95.1 \\
\hline 13 & Carnivora & Galictis cuja & ambulatory & MLP 2020 \\
\hline 16 & Carnivora & Lycalopex gymnocercus & cursorial & MLP 1896 \\
\hline 17 & Carnivora & Meles meles & digger & MACN 5.36 \\
\hline 18 & Carnivora & Nasua nasua & ambulatory & MACN 5.12 \\
\hline 19 & Carnivora & Potos flavus & climber & MLP 1740 \\
\hline 20 & Carnivora & Procyon cancrivorus & ambulatory & MLP 2110 \\
\hline 21 & Primates & Cebus apella & climber & MLP 18.XI.99.8 \\
\hline 22 & Primates & Daubentonia madagascariensis & climber & MACN 12.16 \\
\hline 23 & Notoungulata & Hegetotherium mirabile & - & MPM-PV 4173 \\
\hline 24 & Notoungulata & Interatherium robustum & - & MPM-PV 3527 \\
\hline
\end{tabular}

they were associated with modern perissodactyls (Welker et al. 2015), based on collagen amino acid sequences.

Amongst South American native ungulates, the most morphologically diverse group is the Notoungulata (Simpson 1936; Patterson \& Pascual 1968; Cifelli 1985; Croft 1999), which includes toxodonts and typotheres, considered traditionally as inhabitants of open plains (Patterson \& Pascual 1968; Billet et al. 2009). Typotheres are small to medium-sized animals which bear little resemblance to extant ungulates. Instead, they have been described as similar to hyraxes and mustelids (in the case of Interatheriidae), lagomorphs (for Hegetotheriidae) and capybaras (for Mesotheriidae) (Ameghino 1889; Cope 1897; Sinclair 1909; Bond et al. 1995; Croft 1999; Elissamburu 2004; Elissamburu \& Vizcaíno 2004; Croft \& Anderson 2008; Cassini et al. 2012a). Two typotheres from the early Miocene of Patagonia well represented in the collections are Hegetotherium mirabile (Hegetotheriidae) and Interatherium robustum (Interatheriidae), which were traditionally considered saltatorial and cursorial, respectively (Sinclair 1909). Using ratios with functional importance, of both forelimb and hindlimb, applied in living caviomorph rodents (Elissamburu \& Vizcaíno 2004), the larger $H$. mirabile (body mass around $5 \mathrm{~kg}$; Cassini et al. 2012b) has been characterised as a digger (Elissamburu 2004) or an occasional digger (Cassini et al. 2012a), and the smaller I. robustum (body mass around $2 \mathrm{~kg}$; Cassini et al. 2012b) as a digger (Elissamburu 2004) or an occasional digger with putative swimming or climbing capabilities (Cassini et al. 2012a).

In this contribution, we focus on the relationship between the proximal ulnar articular surface of the ulna and the substrate use by small to medium-sized mammals, in order to assess its usefulness as a proxy for interpreting this disputed paleoecological aspect of $H$. mirabile and I. robustum.

\section{Materials and methods}

We analyzed specimens of 22 living species of eutherians (ten rodents, ten carnivorans and two primates) and two fossil species (typotheres). The comparative sample is composed mostly of rodents and carnivorans, based on the morphological similarities between these and the typotheres, whilst the two primates were included to represent the morphology from an order specialised in climbing. (Table 1).

The ulnae were digitised using a NextEngine Desktop 3-D Scanner, and a 3-D surface mesh was generated (meshes of the fossil ulnae are depicted in Figure 1). The 3-D landmarks coordinates were taken from the mesh using the Landmark editor software (Wiley 2006). Given the complexity of the articular facets and the absence of enough recognisable landmarks, 3-D semi-landmarks were sampled to capture the shape of the proximal articular surfaces. Three landmarks were placed on the most anterior point of the proximal end of the trochlear notch (L1; type II mathematical), the most anterior contact point between the trochlear and radial notches (L2; type I anatomical), and the most lateral contact point between trochlear and radial notches (L3; type I anatomical). L1 coincides with the anconeal process and L2 with the coronoid process (Fig. 1). Forty-two semi-landmarks (type III) were collected on the whole articular surface and three units were defined and separately analysed (Fig. 1): the radial unit comprised the radial notch (L2-3 and 13 semi-landmarks); the distal unit comprised the distal segment of the trochlear notch (L2-3 and 17 semilandmarks); and the proximal unit comprised the proximal segment of the trochlear notch (L1 and 15 semi-landmarks).

The ecomorphological analytical procedures evaluate the relationships of the elbow articular surface with the substrate use. In doing so, we defined five categories: (1) climber; (2) 
(1)

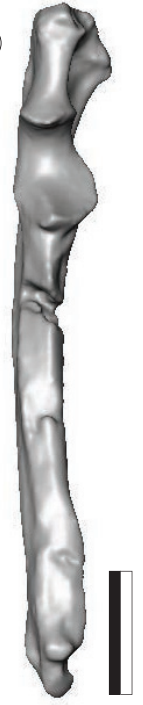

(2)

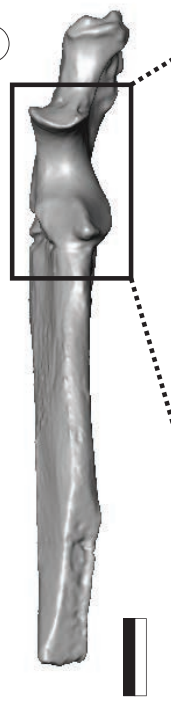

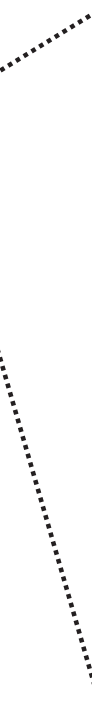
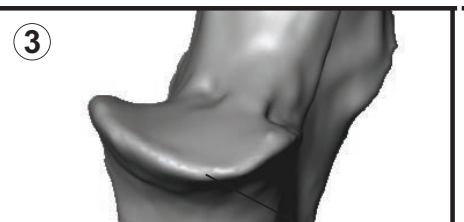

$\mathrm{Tn}$

$\mathrm{Rn}$
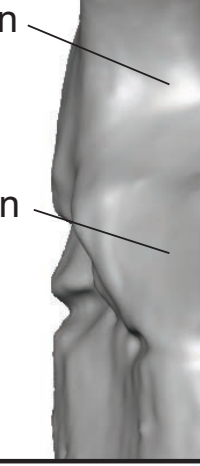

Ancp

Figure 1 (1) Ulna of Interatherium robustum. (2) Ulna of Hegetotherium mirabile. (3) Detail of ulnar proximal articular surface of $H$. mirabile. Abbreviations: Ancp = anconeal process; $\mathrm{Cp}=$ coronoid process; $\mathrm{Rn}=$ radial notch; $\mathrm{Tn}=$ trochlear notch. (4) Same detail showing the three landmarks (red); the 42 semi-landmarks (black); and the three units of analysis: radial (yellow), distal (green) and proximal (light blue). Scale bar $=10 \mathrm{~mm}$.

digger; (3) swimmer; (4) runner; (5) jumper; and (6) ambulatory, for those with no clear predominant activity (following, in part, Morgan \& Álvarez 2013). Substrate use assignation was based on information available in the literature (Van Valkenburgh 1987; Nowak \& Walker 1991; McClearn 1992; Samuels \& Van Valkenburgh 2008; Seckel \& Janis 2008; MeachenSamuels \& Van Valkenburgh 2009) (Table 1). We note that Myocastor coypus is considered here to be a digger because this species uses its forelimb to dig. However, this rodent could be classified also as a swimmer (Samuels \& Van Valkenburgh 2008). The latter option is considered as well (see below).

The whole landmark configurations were superimposed using the generalised Procrustes analysis (GPA) and semi-landmarks were relaxed at the same time using the geomorph 2.1.3 package (Adams \& Otárola-Castillo 2013) in R software 3.1.5 (R Development Core Team 2015). The semi-landmarks on the limits of each surface (trochlear and radial) were treated as curves, and the ones inside the limits were treated as surfaces (giving them more degrees of freedom to slide). The landmarks belonging to each articular unit (radial, distal and proximal) were selected from the superimposed and relaxed configuration, and a new GPA without relaxation was made in order to generate their own shape space (accounting for four shape spaces). We performed a principal component analysis (PCA) to identify the major components of the variation related to taxonomic and ecological distribution of extant taxa and the constitution of informative morphospaces.

Four PCA analyses were undertaken: (1) for the whole articular facet (PCAw); (2) for the radial notch (PCAr); (3) for the distal segment of the trochlear notch (PCAd); and (4) for the proximal segment of the trochlear notch (PCAp). Following Cardini et al. (2010) and Abba et al. (2015), the correlation between two distance matrices, euclidean distances (PCs) and procrustes distances in the full shape space, was calculated and used to determine the number of principal components to explore. The correlation coefficients were plotted onto the number of PCs, and the PC at the "elbow" in the plot was taken as the highest $\mathrm{PC}$ to retain (Cardini et al. 2010). Visualisation and graphics were made using the Morpho R package 2.3.1.1 (Schlager 2013), which allowed the colour pattern to be associated with the shape changes. Statistical analyses were performed using R software.
Institutional abbreviations. The specimens are housed in the following institutions: Centro Nacional Patagónico, Puerto Madryn, Argentina (CNP); Museo Argentino de Ciencias Naturales "Bernardino Rivadavia", Ciudad Autónoma de Buenos Aires, Argentina (MACN); Museu de Ciencias Naturais, Porto Alegre, Brasil (MCN); Museo de La Plata, La Plata, Argentina (MLP); Museo Municipal de Ciencias Naturales Lorenzo Scaglia (MMPMa); Museo Regional Provincial Padre M. Jesús Molina, Río Gallegos, Argentina (MPM-PV).

\section{Results}

In the bi-plot of the correlation coefficients versus the number of PCs for each PCA, the "elbow" point was at the fifth PC. Therefore, the first five PCs were selected to explore the morphospace structure (Table 2). The correlations between the distance matrix of the first five PCs and the full shape space distance matrix was greater than 0.95 in every case. In all PCAs, the first component shows a strong taxonomic signal, distinguishing carnivorans from rodents and, amongst all the analyses, only PCAp showed a clear functional signal in both PC1 and PC2 individually. However, on the other PCAs, an unclear functional pattern sometimes emerged only in the morphospace depicted by $\mathrm{PC} 1$ and 2 taken together. The remaining principal components were uninformative, with the exception of PC3 in PCAw and PCAr, which in both cases presented a similar taxonomic signal to that seen on PC1 of all analyses. As no PC beyond PC2 showed functional signal (see Table 2), only PC1 and PC2 of each analysis are described and used in the following interpretations.

The first five PCs of the whole articular surface analysis (PCAw; Fig. 2) account for $\sim 75 \%$ of cumulative variance (Table 2), and the first two PCs account for $\sim 40 \%$ of the total variance. On PC1 $(\sim 24 \%)$, there is a variation from strong proximodistal difference in the width (with a narrower proximal part), a high trochlear notch, a strong mediolateral convexity and a quadrangular radial notch in negative values, to sub-equal distal and proximal widths, low trochlear notch mediolateral convexity and a more triangular radial notch toward positive values. The carnivorans mostly have negative values, the primates are close to zero, and the rodents have mostly positive values. 
Table 2 Explained variances and reduced space-full space correlation of all PCAs. \% Var. = percent of variance explained by each PC;

Cum.Var. $\%=$ Cumulative variance percent; Space Corr. = correlation coefficients between the reduced space (first five PCs) and full shape space; $*=$ presence of functional signal; $\$=$ presence of taxonomic signal.

\begin{tabular}{|c|c|c|c|c|c|}
\hline & & PCAw & PCAr & PCAd & PCAp \\
\hline \multirow{5}{*}{$\%$ Var. } & $\mathrm{PC} 1$ & $23.528 \%$ & $40.164 \ddagger$ & $25.759 \$$ & $34.666^{*} / \hbar$ \\
\hline & PC2 & 16.674 & 23.515 & 22.334 & $20.387^{*}$ \\
\hline & PC3 & $15.458 \$$ & $12.441 \%$ & 21.208 & 14.983 \\
\hline & PC4 & 10.723 & 7.194 & 10.558 & 10.056 \\
\hline & PC5 & 8.497 & 6.375 & 6.588 & 5.731 \\
\hline \multirow{2}{*}{\multicolumn{2}{|c|}{$\begin{array}{l}\text { Cum. Var. \% } \\
\text { Space Corr. }\end{array}$}} & 74.88 & 89.688 & 86.448 & 85.822 \\
\hline & & 0.9721 & 0.9928 & 0.9905 & 0.9839 \\
\hline
\end{tabular}

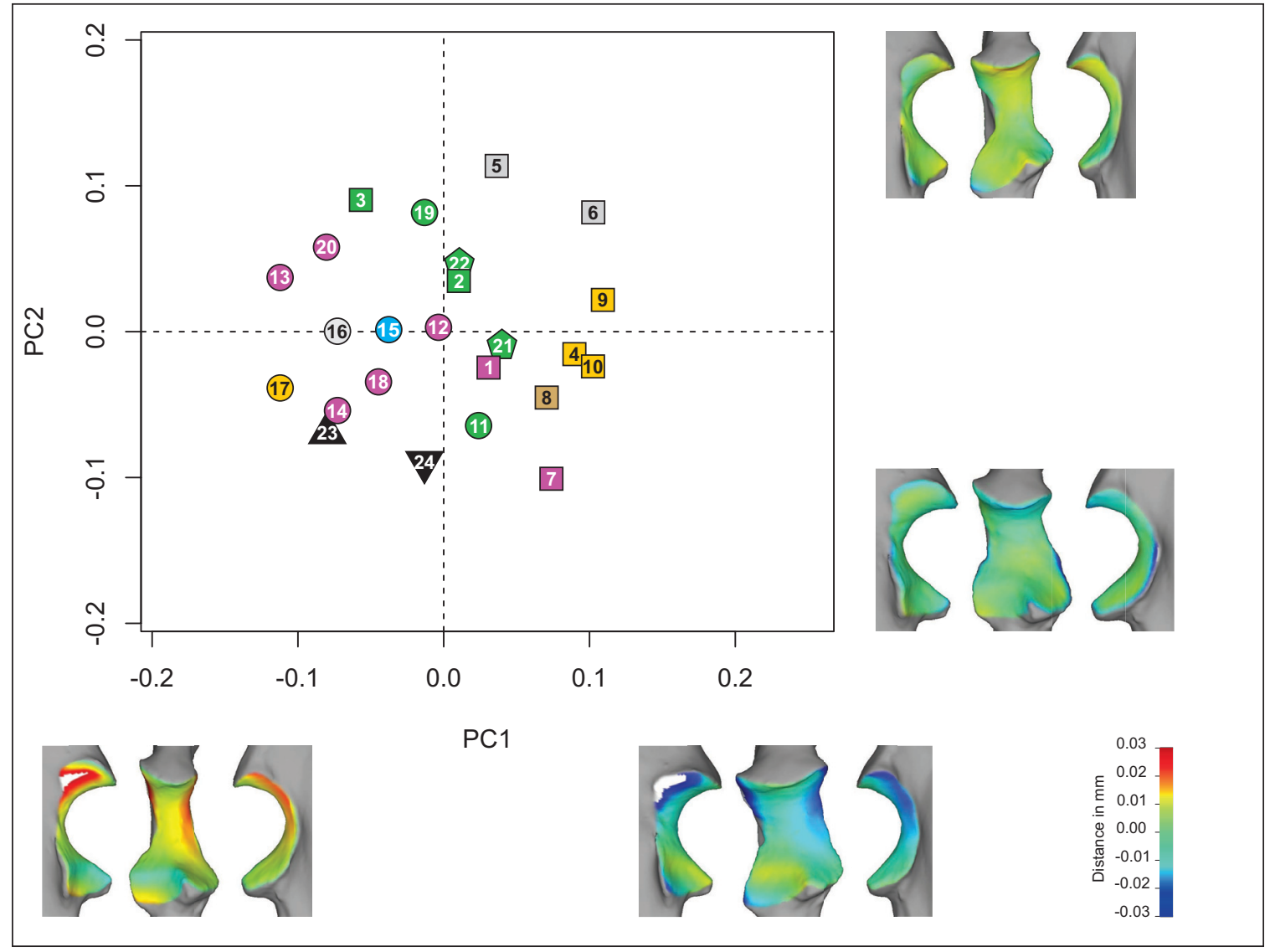

Figure 2 PCAw. Taxa distribution in the morphospace defined by the first two PCs. Shape (lateral, anterior and medial views) of extreme negative and positive values of each component (PC1, bottom; PC2, right). Taxa reference: squares = rodents; pentagons = primates; circles = carnivorans; triangle $=H$. mirabile; inverted triangles $=I$. robustum. Substrate use reference: green $=$ climbers; yellow $=$ diggers; light blue $=$ swimmers; grey $=$ runners; brown $=$ jumpers; violet $=$ ambulatory .

On PC2 $(\sim 17 \%)$, there is variation in width (from wide to narrow), in the proximodistal curvature in the sagittal plane (from high to low concavity) and in the anterior projection of the coronoid process (from more to less projected). There is no clear taxonomic pattern on PC2 in the PCAw analysis.

The only substrate use category identifiable on PC1 and PC2 of the PCAw morphospace is represented by the digging rodents of this sample (including the coypu, $M$. coypus), which have high values of PC1 and mid-range values of PC2. The typotheres fall in the boundary of the morphospace of the total extant sample, with negative values of both PCs, sharing the PC1 values with the carnivorans. The PCAw does not show a clear functional segregation (with exception of digging rodents), but there is an identifiable taxonomic cluster on PC1.
In the radial notch unit analysis (PCAr; Fig. 3), the first five PCs account for almost $90 \%$ of cumulative variance (Table 2), with the first two accounting for $\sim 64 \%$ of the total variation. On PC1 $(\sim 40 \%)$, the shape of the radial notch varies from quadrangular and elongated, with no curvature on the negative side, to semi-triangular and broad, with some degree of proximodistal concavity in the sagittal plane on the positive side. Most of the carnivorans have negative values on PC1, whereas primates and most rodents tend to have positive values. On PC2 ( 24\%), the shape varies, starting on the negative and ending on the positive side, from oval-shaped to elongated semi-triangular; but the more conspicuous change is seen in the curvature: from flat to concave (both mediolaterally in the transversal plane and proximodistally in the sagittal 


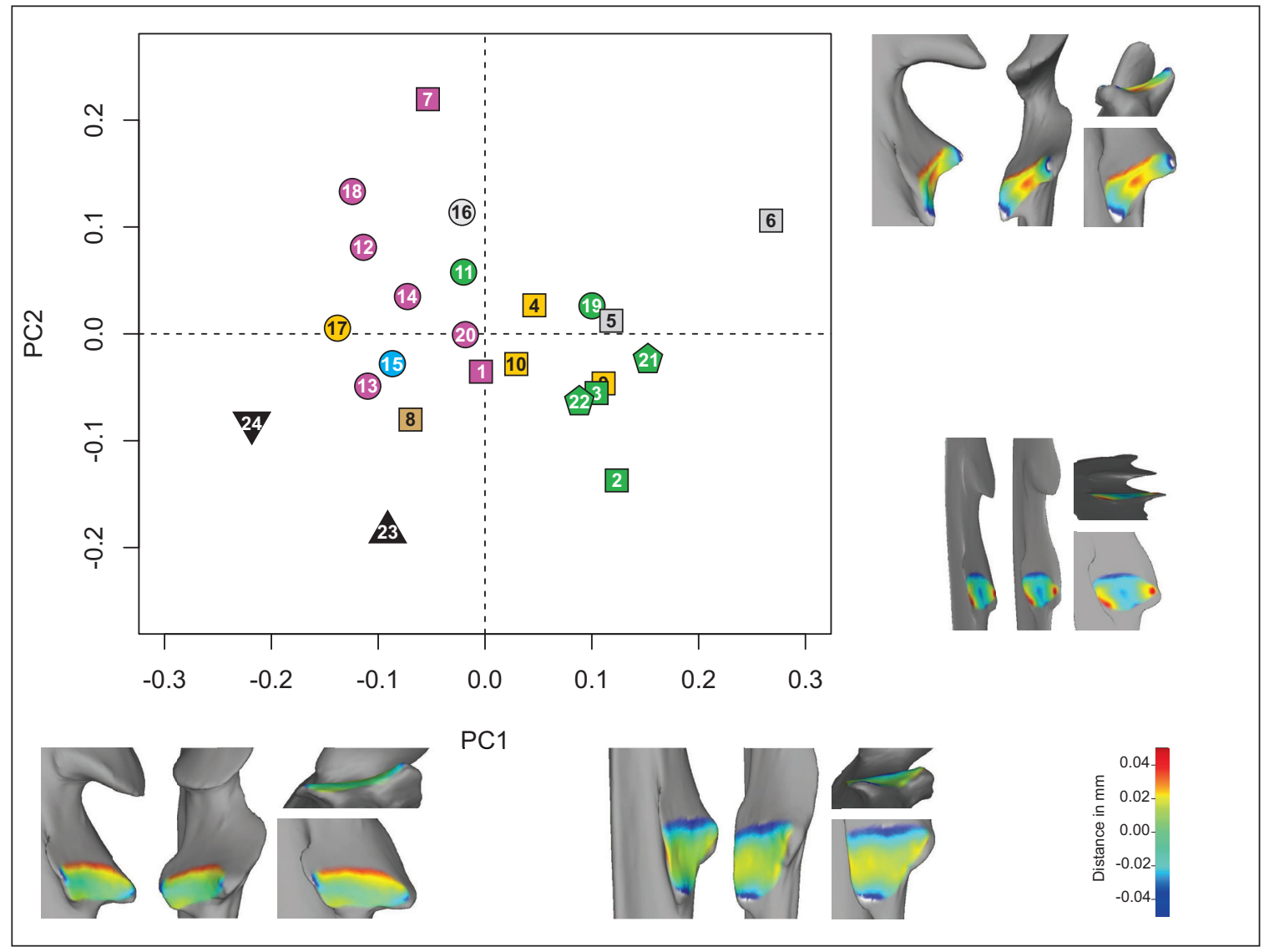

Figure 3 PCAr. Taxa distribution in the morphospace defined by the first two PCs. Shape (lateral, anterior, distal and anterolateral views) of extreme negative and positive values of each component (PC1, bottom; PC2, right). Taxa reference: squares $=$ rodents; pentagons $=$ primates; circles $=$ carnivorans; triangle $=H$. mirabile; inverted triangles $=I$. robustum. Substrate use reference: green $=$ climbers; yellow $=$ diggers; light blue $=$ swimmers; grey $=$ runners; brown $=$ jumpers; violet $=$ ambulatory

plane). On this PC, no taxonomic or functional arrangement is detected. The morphospace depicted by $\mathrm{PC} 1$ and PC2 partially reflects a shared morphology between several climbers and diggers. The typotheres lie outside the point cloud of the extant sample, with $I$. robustum on the extreme negative value of $\mathrm{PC} 1$ and $H$. mirabile on the extreme negative value of PC2, both sharing partially the carnivoran values of PC1.

For the distal unit analysis (PCAd; Fig. 4), the first five PCs account for $\sim 87 \%$ of the total variation (Table 2 ), with a cumulative variance of $\sim 48 \%$ on the first two PCs. On PC1 ( $\sim 26 \%)$, shape variables associated with low values include distally protruding medial and lateral borders, more proximodistal convexity in the sagittal plane, less projecting coronoid processes, and a mediolateral curvature in the anteroposterior plane approaching $180^{\circ}$. Conversely, high $\mathrm{PC} 1$ values reflect less protruding medial and lateral borders, lower proximodistal convexity in the sagittal plane, a slightly more projecting coronoid process and a mediolateral curvature in the anteroposterior plane closer to $90^{\circ}$. Most of the carnivorans have negative values and most of the rodents have positive values, with the primates occupying the middle values.

On PC2 $(\sim 22 \%)$, shape varies from more proximodistally convex in the sagittal plane and proportionally narrower intermediate width to less proximodistally convex and wider intermediate width towards the positive end. There is no evident taxonomic or functional arrangement on this PC. Typotheres lie among the rodents in the morphospace depicted by the first and second PCs. The PCAd is the one with the more obscure pattern, with most of the functional types mixed and occupying and extended area of this morphospace.
In the proximal unit analysis (PCAp; Fig 5), the first five PCs account for $\sim 86 \%$ of the cumulative variance (Table 2 ), with the first two PCs accounting for $\sim 55 \%$ of the total variation. On PC1 $(\sim 35 \%)$, the shapes associated with low values have a narrower trochlear notch, whereas those with higher values have a wider notch. There is a taxonomic pattern, with most of the carnivorans on the negative side and the primates and most of the rodents on the positive side. Amongst rodents, diggers lie on the extreme positive values, separated from the other categories.

On PC2 (accounting for 20\% of the variance), higher values correspond to mediolaterally convex surfaces with the proximal width greater than intermediate width, whilst lower values correspond to mediolaterally flattened surfaces and proximal versus intermediate width being sub-equal. Most climbers (from three different orders) have positive values, whereas runners and jumpers have negative values (although mixed with some ambulatory species); the lowest value is for the runner Lycalopex gymnocercus.

In the morphospace depicted by the first two PCs taken together, two categories are distinct: climbers (except for the squirrel Callosciurus erythraeus) have midrange values of PC1 and high values of $\mathrm{PC} 2$; digging rodents have high values of $\mathrm{PC} 1$ and midrange values of PC2. Amongst the carnivorans, there is a gradient starting with runners (low values of PC1 and PC2), passing through ambulatory and digging taxa and swimmers and culminating with climbers. Considering only the rodents, there is no clear separation between runners and ambulatory taxa. The typothere $H$. mirabile lies closest to ambulatory carnivorans and ambulatory and running rodents. 


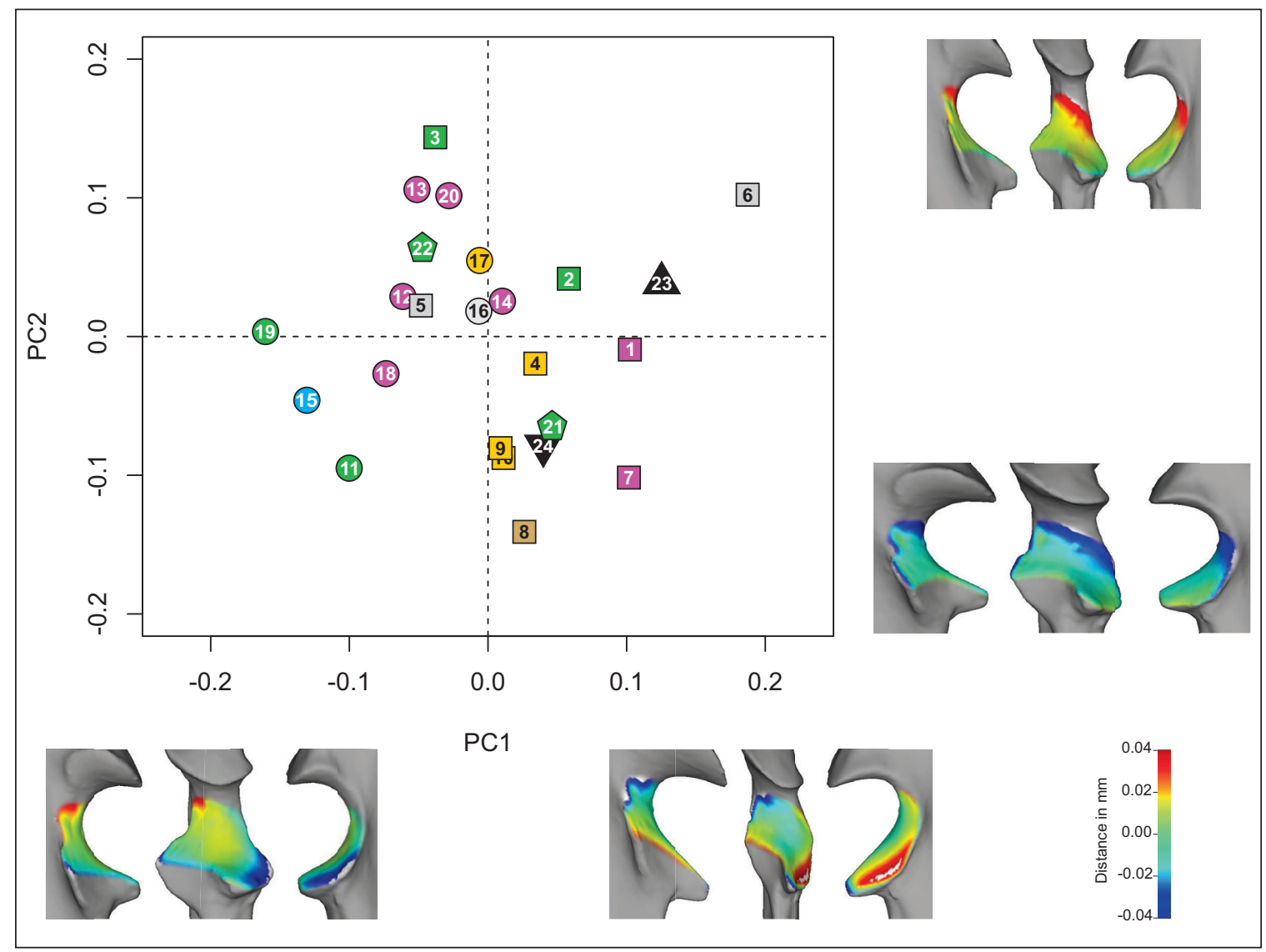

Figure 4 PCAd. Taxa distribution in the morphospace defined by the first two PCs. Shape (lateral, anterior and medial views) of extreme negative and positive values of each component (PC1, bottom; PC2, right). Taxa reference: squares $=$ rodents; pentagons $=$ primates; circles $=$ carnivorans; triangle $=H$. mirabile ; inverted triangles $=$ I. robustum. Substrate use reference: green = climbers; yellow = diggers; light blue = swimmers; grey $=$ runners; brown $=$ jumpers; violet $=$ ambulatory.

I. robustum has its own morphospace, with low values of PC2, like the runner L. gymnocercus and the jumper Lagidium viscacia.

\section{Discussion}

The PCAr does not show a clear functional pattern. According to Taylor (1974), the supination of the antebrachium is facilitated by a shallow radial notch, a feature shown by the shape change toward the negative PC2. This characteristic is expected in climbers, because of the need for a greater degree of supination. As can be seen on the PCAr (Fig. 3), climbers and diggers share the morphospace depicted by negative values of PC2 and positive of values PC1 (with the exception of the digging carnivore Meles meles). The shape associated with this quadrant is a triangular and flattened radial notch. Taylor (1974) also stated that the radial notch is flatter in fossorial species that require a flexible manus for digging, in agreement with our results. Typotheres occupy an exclusive morphospace, with a flattened and quadrangular radial notch, quite distant from the extant digger-climber morphospace. Consequently, our results from the study of the ulna do not suggest that typotheres had good digging capabilities (Elissamburu 2004). Nor is there evidence from the ulna of climbing activities for I. robustum (Cassini et al. 2012a). We point out, however, that that $M$. meles (digger) also deviates from the expected morphology.

In the PCAd (Fig. 4), there is an evident segregation on PC1 between carnivorans (negative side) and rodents (positive side). Typotheres fall in the rodent morphospace sharing their shape characteristics: they have a narrow distal width with a pronounced mediolateral curvature in the anteroposterior plane. According to the literature, climbers from different lineages should lie together, sharing an expanded protruded coronoid process related to supporting the weight and liberating the radius when climbing (Argot 2001; Sargis 2002), but we do not find this to be the case in our analysis. As our results do not reflect a functional pattern, the question of why typotheres are convergent with rodents in this feature remains unresolved. However, an interesting hypothesis to test with future work is the possible correlation of these morphologies and the distribution of weight in the body (i.e., the position of the centre of mass). The expansion of this feature could be related to a more anterior position of the centre of mass on carnivorans, whilst the reduction could relate to a more posterior one on rodents and typotheres, where the forelimb would be supporting a smaller proportion of the weight.

In the PCAp (Fig. 5), climbers and diggers occupy distinct areas of the morphospace depicted by PC1 and PC2. Climbers include primates, carnivorans and rodents, with the exception of the squirrel $C$. erythraeus. This species may be distinct owing to its ability to run at high speed over the branches, an activity described by Aprile \& Chico (1999). The fact that different orders with the same substrate use group appear in the same morphospace suggests underlying functional reasons. Wide trochleas increase the contact surface at the elbow joint, which would be effective for resisting the forces generated during climbing. Additionally, a flattened proximal surface would allow a wide range of movements at the elbow joint, 


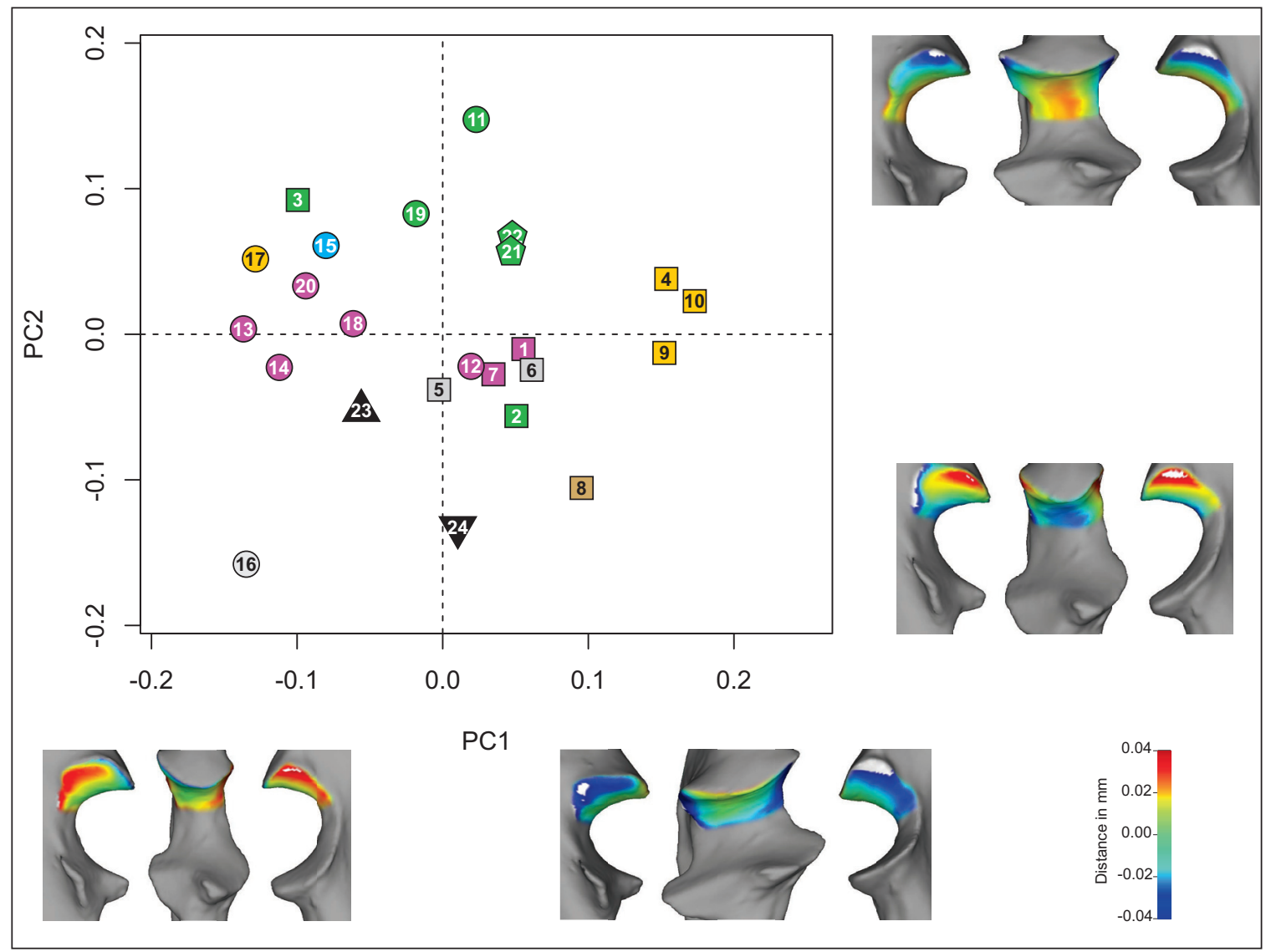

Figure 5 PCAp. Taxa distribution in the morphospace defined by the first two PCs. Shape (lateral, anterior and medial views) of extreme negative and positive values of each component (PC1, bottom; PC2, right). Taxa reference: squares $=$ rodents; pentagons $=$ primates; circles $=$ carnivorans; triangle $=H$. mirabile; inverted triangles $=I$. robustum . Substrate use reference: green = climbers; yellow $=$ diggers; light blue $=$ swimmers; grey $=$ runners; brown $=$ jumpers; violet $=$ ambulatory.

required to grasp new supports and to facilitate directional changes during climbing (see Fig. 5). In the case of most forelimb diggers (again with the exception of M. meles), a wide trochlea increases the contact surface at the elbow joint, an advantageous feature both for stability and to provide more robusticity for resisting the large forces produced during digging. In addition, the mediolateral convexity of the proximal trochlear (including the anconeal process) would improve the stability and minimise possible dislocations (increasing the congruence between humerus and ulna) at the elbow joint. If we had classified M. coypus as a swimmer (Samuels \& Van Valkenburgh 2008), our results would be consistent with previous studies that indicate convergent features between diggers and swimmers associated with large forces produced by the forelimbs (Elissamburu \& Vizcaíno 2004).

The fact that the group of diggers in this area of the morphospace is composed only of rodents (Ctenomys australis, Lagostomus maximus and M. coypus) may suggest that they group together due to phylogenetic reasons. However, it must be considered that they belong to different families and that other rodents with different substrate use are not near them. In contrast, phylogenetic effects can be acting in the case of M. meles, which groups together with the remaining carnivorans at the opposite end of PC1 (reflecting the strong taxonomic segregation seen in all analyses). On the other hand, runners do not cluster together. Both running rodents group with ambulatory rodents, and are distinct from carnivorans. The only running carnivoran (Lycalopex gymnocercus) occupies its own morphospace, far from the ambulatory carnivorans. Therefore, the specialisation for running in each clade must have been achieved through different morphological pathways. Amongst typotheres, H. mirabile lies near ambulatory and running species, as would be expected for an small ungulate living in an open habitat (Cassini 2013). For I. robustum, the results are not conclusive, because it is in its own morphospace and has no clear resemblance to any known substrate-use category. Furthermore, neither typothere can be characterised as a climber or digger, as they are far apart from the corresponding morphospace, in disagreement with previous hypotheses on substrate use for these species.

In summary, runners seem to have different proximal ulnar morphologies in different clades. For example, in our sample, the running carnivore L. gymnocercus never shares a restricted morphospace with the running rodents Dolichotis patagonum and Dasyprocta azarae. Consequently, there is no common morphology clearly related with this particular mode of locomotion within the substrate use. Something similar occurs with diggers, with the carnivore $M$. meles positioned apart from other diggers. Nonetheless, there is a similarity among digging rodents and they are distinct with respect to the other groups. None of the analyses recovers a gradient or sequence from running to the rest of specialisations, such the cursorialgeneralise-occasional digging-diggers functional sequence described by Elissamburu \& Vizcaíno (2004).

We identify a convergent morphology for the proximal unit of the proximal ulnar articular surface amongst all climbers in our sample, with the exception of the squirrel. This morphology varies between narrow and wide, but mostly is intermediate, and tends to present a less mediolaterally convex surface in the anteroposterior plane in comparison with the rest of the sample, 
and a wider proximal moiety compared to the intermediate width. In the same unit, there is a morphological congruence for digging rodents, with wide and convex morphologies.

Neither typothere would have been specialised for either climbing or digging in the proximal ulnar articular facet morphology analysed here. Furthermore, depending on the unit of analysis, they can have their own morphospace or share it with carnivorans or rodents. This segregation of carnivorans and rodents on PC1 is shown on every analysis, and reflects a considerable amount of taxonomic influence in the morphospace.

As the first PCA (PCAw; Fig. 2) does not show any clear functional arrangement on the morphospace, it was assumed that different patterns could be interfering with each other. If there are different morphological change trends in different portions of a joint, a whole facet analysis could show mixed results. These trends could exist due to dissimilar mechanical stress, or to phylogenetic constraints (or a combination of both). Notably, in the set of analysis, there is much variation between PCAs, with a substantially different arrangement depending on the set of landmarks analysed. These morphological dissimilarities are interpreted, at least partially, as differential responses to different kinds of mechanical stress (e.g., climbing morphology for the proximal unit).

Further work must be done, including the study of more species and analysing other joints of the forelimb and hindlimb. Interpreting the results of several articular facets will help elucidate substrate use and locomotion in extinct mammals.

\section{Acknowledgments}

The authors wish to thank the following people and institutions: the Editors of the Special Issue on Form, Function and Palaeobiology, for inviting us to participate; Dirección de Patrimonio Cultural and Museo Regional Provincial Padre M. J. Molina (Río Gallegos, Argentina); D. Verzi and I. Olivares (MLP), D. Flores and S. Lucero (MACN), U.F.J. Pardiñas (CNP) and D. Romero (MMPMa) for access to mammalogy collections; N. Toledo for his continuous help; R. F. Kay and the reviewers M. Reguero and P. Cox for valuable suggestions and corrections that greatly enhanced this manuscript. This is a contribution to projects PICT 2013-0389 (ANPCyT), PIP 1054 (CONICET), and N750 (UNLP) to SFV.

\section{References}

Abba, A. M., Cassini, G. H., Valverde, G., Tilak, M.-K., Vizcaíno, S. F., Superina, M. \& Delsuc, F. 2015. Systematics of hairy armadillos and the taxonomic status of the Andean hairy armadillo (Chaetophractus nationi). Journal of Mammalogy 96(4), 673-89.

Adams, D. C. \& Otárola-Castillo, E. 2013. geomorph: an R package for the collection and analysis of geometric morphometric shape data. Methods in Ecology and Evolution 4, 393-99.

Ameghino, F. 1889. Contribución al conocimiento de los mamíferos fósiles de la República Argentina. Actas de la Academia Nacional de Ciencias de Cordoba 6, 1-1027.

Andersson, K. I. 2004. Elbow-joint morphology as a guide to forearm function and foraging behaviour in mammalian carnivores. Zoological Journal of the Linnean Society 142, 91-104.

Aprile, G. \& Chico, D. 1999. Nueva especie exótica de mamífero en la Argentina: la ardilla de vientre rojo (Callosciurus erythraeus). Mastozoología Neotropical 6, 7-14.

Argot, C. 2001. Functional-adaptive anatomy of the forelimb in the Didelphidae, and the paleobiology of the Paleocene marsupials Mayulestes ferox and Pucadelphys andinus. Journal of Morphology 247, 51-79.

Billet, G., Blondel, C. \& de Muizon, C. D. 2009. Dental microwear analysis of notoungulates (Mammalia) from Salla (Late Oligocene, Bolivia) and discussion on their precocious hypsodonty. Palaeogeography, Palaeoclimatology, Palaeoecology 274, 114-24.
Bond, M., Cerdeño, E. \& López, G. M. 1995. Los ungulados nativos de América del Sur. In Alberdi, M. T., Leone, G., Tonni, E. P. (eds) Evolución biológica y climática de la región Pampeana durante los últimos cinco millones de años. Un ensayo de correlación con el Mediterráneo occidental, 259-75. Madrid: CSIC.

Candela, A. M. \& Picasso, M. B. 2008. Functional anatomy of the limbs of Erethizontidae (Rodentia, Caviomorpha): Indicators of locomotor behavior in Miocene porcupines. Journal of Morphology 269, 552-93.

Cardini, A., Filho, J. A. F. D., Polly, P. D. \& Elton, S. 2010. Biogeographic Analysis Using Geometric Morphometrics: Clines in Skull Size and Shape in a Widespread African Arboreal Monkey. In Elewa, M. T. A. (ed.) Morphometrics for Nonmorphometricians, 191-217. Berlin, Heidelberg: Springer.

Cassini, G. H. 2013. Skull geometric morphometrics and paleoecology of Santacrucian (late early Miocene; Patagonia) native ungulates (Astrapotheria, Litopterna, and Notoungulata). Ameghiniana 50, 193-216.

Cassini, G. H., Cerdeño, E., Villafañe, A. L. \& Muñoz, N. A. 2012a. Paleobiology of Santacrucian native ungulates (Meridiungulata: Astrapotheria, Litopterna and Notoungulata). In Vizcaíno, S. F., Kay, R. F. \& Bargo, M. S. (eds) Early Miocene Paleobiology in Patagonia: High-Latitude Paleocommunities of the Santa Cruz Formation, 243-86. Cambridge: Cambridge University Press.

Cassini, G. H., Vizcaíno, S. F. \& Bargo, M. S. 2012b. Body mass estimation in Early Miocene native South American ungulates: a predictive equation based on 3D landmarks. Journal of Zoology 287, 53-64.

Cifelli, R. L. 1985. South American ungulate evolution and extinction. In Stehli, F. G. \& Webb, S. D. (eds) The Great American Biotic Interchange, 249-66. New York: Plenum Press.

Cope, E. D. 1897. Toxodontia. The American Naturalist 31, 485-92.

Croft, D. A. 1999. Placentals: endemic South American ungulates. In Singer, R. (ed.) The Encyclopedia of Paleontology, 890-906. Chicago: Fitzroy-Dearborn. 1550 pp.

Croft, D. A. \& Anderson, L. C. 2008. Locomotion in the extinct notoungulate Protypotherium. Palaeontologia Electronica 11, 1-20.

Drapeau, M. S. 2008. Articular morphology of the proximal ulna in extant and fossil hominoids and hominins. Journal of human evolution 55, 86-102.

Elissamburu, A. 2004. Análisis morfométrico y morfofuncional del esqueleto apendicular de Paedotherium (Mammalia, Notoungulata). Ameghiniana 41, 363-80.

Elissamburu, A. \& Vizcaíno, S. F. 2004. Limb proportions and adaptations in caviomorph rodents (Rodentia: Caviomorpha). Journal of Zoology 262, 145-59.

Ercoli, M. D., Prevosti, F. J. \& Álvarez, A. 2012. Form and function within a phylogenetic framework: locomotory habits of extant predators and some Miocene Sparassodonta (Metatheria). Zoological Journal of the Linnean Society 165, 224-51.

Fabre, A. C., Cornette, R., Slater, G., Argot, C., Peigne, S., Goswami, A. \& Pouydebat, E. 2013. Getting a grip on the evolution of grasping in musteloid carnivorans: a three-dimensional analysis of forelimb shape. Journal of Evolutionary Biology 26, 1521-35.

Horovitz, I. 2004. Eutherian mammal systematics and the origins of South American ungulates as base on postcranial osteology. In Dawson, M. R. \& Lillengraven, J. A. (eds) Fanfare for an uncommon paleontologist: Papers in honor of Malcom C. McKenna. Bulletin of Carnegie Museum of Natural History 36, 63-79.

Jenkins, F. A., Jr. 1973. The functional anatomy and evolution of the mammalian humero-ulnar articulation. The American Journal of Anatomy 137, 281-97.

McClearn, D. 1992. Locomotion, Posture and Feeding Behavior of Kinkajous, Coatis and Raccoons. Journal of Mammalogy 73, 24561.

Meachen-Samuels, J. \& Van Valkenburgh, B. 2009. Forelimb indicators of prey-size preference in the Felidae. Journal of Morphology 270, $729-44$.

Miljutin, A. 2009. Substrate utilization and feeding strategies of mammals: description and classification. Estonian Journal of Ecology 58(1), 60-71.

Morgan, C. C. \& Álvarez, A. 2013. The humerus of South American caviomorph rodents: shape, function and size in a phylogenetic context. Journal of Zoology 290, 107-16.

Nowak, R. M. \& Walker, E. P. 1991. Walker's Mammals of the World, 2015. Baltimore: Johns Hopkins University Press.

O’Leary, M. A., Bloch, J. I., Flynn, J. J., Gaudin, T. J., Giallombardo, A., Giannini, N. P., Goldberg, S. L., Kraatz, B. P., Luo, Z.-X., Meng, J., Ni, X., Novacek, M. J., Perini, F. A., Randall, Z. S., Rougier, G. W., Sargis, E. J., Silcox, M. T., Simmons, N. B., Spaulding, M., Velazco, P. M., Weksler, M., Wible, J. R. \& 
Cirranello, A. L. 2013. The placental mammal ancestor and the Post-K-Pg radiation of placentals. Science 339, 662-67.

Patterson, B. \& Pascual, R. 1968. The fossil mammal fauna of South America. The Quarterly Review of Biology 43, 409-51.

R Development Core Team. 2015. R: A language and environment for statistical computing. Vienna, Austria: R Foundation for Statistical Computing.

Samuels, J. X. \& Van Valkenburgh, B. 2008. Skeletal indicators of locomotor adaptations in living and extinct rodents. Journal of Morphology 269, 1387-1411.

Sargis, E. J. 2002. Functional morphology of the forelimb of tupaiids (Mammalia, Scandentia) and its phylogenetic implications. Journal of Morphology 253, 10-42.

Schlager, S. 2013. Morpho: Calculations and visualizations related to Geometric Morphometrics. R package version 0.25-1. http:// CRAN.R-project.org $/$ package $=$ Morpho

Seckel, L. \& Janis, C. 2008. Convergences in Scapula Morphology among Small Cursorial Mammals: An Osteological Correlate for Locomotory Specialization. Journal of Mammalian Evolution 15, 261-79.

Simpson, G. G. 1936. Structure of a primitive Notoungulate cranium. American Museum Novitates 824, 1-31.

Sinclair, W. J. 1909. Mammalia of the Santa Cruz beds. Part I. Typotheria. In Scott, W. B. (ed.) Reports of the Princeton University Expeditions to Patagonia, 1896-1899, 1-110. Princeton: Princeton University.

Szalay, F. S. \& Sargis, E. J. 2001. Model-based analysis of postcranial osteology of marsupials from the Palaeocene of Itaboraí (Brazil) and the phylogenetics and biogeography of Metatheria. Geodiversitas 23, 139-302.
Taylor, M. E. 1974. The functional anatomy of the forelimb of some African viverridae (Carnivora). Journal of Morphology 143, 30735.

Toledo, N., Bargo, M. S., Cassini, G. H. \& Vizcaíno, S. F. 2012. The Forelimb of Early Miocene Sloths (Mammalia, Xenarthra, Folivora): Morphometrics and Functional Implications for Substrate Preferences. Journal of Mammalian Evolution 19, 185-98.

Toledo, N., Bargo, M. S. \& Vizcaíno, S. F. 2013. Muscular reconstruction and functional morphology of the forelimb of early Miocene sloths (Xenarthra, Folivora) of Patagonia. The Anatomical Record 296, 305-25.

Van Valkenburgh, B. 1987. Skeletal indicators of locomotor behavior in living and extinct carnivores. Journal of Vertebrate Paleontology 7, $162-82$.

Vizcaíno, S. F., Kay, R. F. \& Bargo, S. 2012. Early Miocene Paleobiology in Patagonia: High-Latitude Paleocommunities of the Santa Cruz Formation. Cambridge: Cambridge University Press. 370 pp.

Welker, F., Collins, M. J., Thomas, J. A., Wadsley, M., Brace, S., Cappellini, E., Turvey, S. T., Reguero, M., Gelfo, J. N., Kramarz, A., Burger, J., Thomas-Oates, J., Ashford, D. A., Ashton, P. D. Rowsell, K., Porter, D. M., Kessler, B., Fischer, R., Baessmann, C., Kaspar, S., Olsen, J. V., Kiley, P., Elliott, J. A., Kelstrup, C. D., Mullin, V., Hofreiter, M., Willerslev, E., Hublin, J. J. Orlando, L., Barnes, I. \& MacPhee, R. D. 2015. Ancient proteins resolve the evolutionary history of Darwin's South American ungulates. Nature 522, 81-84.

Wiley, D. F. 2006. Landmark Editor 3.0. Davis, CA: Institute for Data Analysis and Visualization, University of California. (http://graphics.idav.ucdavis.edu/research/EvoMorph).

MS received 1 June 2015. Accepted for publication 26 July 2016. 
